\title{
Evaluation of the usability of single extractors in chemical analysis of composts using principal component analysis
}

\author{
Monika Jakubus ${ }^{1}$, Małgorzata Graczyk ${ }^{2}$ \\ ${ }^{1}$ Department of Soil Science and Land Protection, , Poznan University of Life Sciences \\ Szydłowska 50, 60-656 Poznań, Poland, e-mail: monja@up.poznan.pl \\ ${ }^{2}$ Department of Mathematical and Statistical Methods, Poznan University of Life Sciences \\ Wojska Polskiego 28, 60-637 Poznań, Poland, e-mail: magra@up.poznan.pl
}

\section{SUMMARY}

\begin{abstract}
The usability of various single extractors in the chemical analysis of composts was evaluated using principal component analysis. Ten different single extractors were used to determine the contents of microelements obtained in the chemical extraction of four different composts. It was found that principal component analysis is a satisfactory statistical method enabling the comparison of different solutions in terms of efficiency of extraction of microelements from composts of different composition. The results showed that $1 \mathrm{~mol} \mathrm{dm}^{-3} \mathrm{HCL}$ and $10 \% \mathrm{HNO}_{3}$ solutions had the highest extraction strength, and $0.01 \mathrm{~mol} \mathrm{dm}^{-3} \mathrm{CaCl}_{2}$ and $1 \mathrm{~mol} \mathrm{dm}^{-3} \mathrm{NH}_{4} \mathrm{NO}_{3}$ the lowest.
\end{abstract}

Key words: composts, microelements, principal component analysis, single extractors

\section{Introduction}

Composting of sewage sludge together with other structure-forming waste materials is a common and generally accepted method of disposal for this noxious waste. The composts thus produced are valuable sources of nutrients and organic matter, which is of significant importance in agricultural and horticultural production. It is clear that the nutritive value of composts is dependent on several factors, ranging from the components used to the type and conditions of the composting process. It should be noted that combinations of macro- and micronutrients in compost are of great practical importance. Nutrients in compost may be found in various forms, characterised by varying levels of bioavailability, which determine the rate of their release from compost 
and thus the degree of their availability to plants. As has been reported in the literature (Fuentes et al. 2004, Jakubus 2010, 2012), the bioavailability of micronutrients from composts depends on the chemical forms and the binding of elements with organic matter, where ionic forms are considered to be readily available in the form of simple or complexing ions, as well as readily watersoluble forms, exhibiting exchange adsorption. Forms bound to organic matter or incorporated in the crystal lattice of the mineral fraction of the compost are less readily available. For this reason, after compost is introduced into the soil, only a portion of the micronutrients found in these forms penetrates to the food chain (Rao et al. 2008). Quantitative analyses of micronutrients in forms available for plants are conducted using single extraction techniques. Single extraction facilitates the separation of the tested environmental matrix into fractions that are soluble and insoluble in a given extracting solution. According to Pijnenburg and Jager (2003), Meers et al. (2007) and Jakubus (2012), the discussed procedures are useful in the determination of chemical forms of components, and thus they facilitate the determination of the suitability of composts and their respective rates of application. Procedures of chemical extraction of individual microelements from composts are based on extraction using water, salt solutions, diluted acids and solutions containing chelating or reducing reagents. Pijnenburg and Jager (2003) and Gupta and Singh (2006) particularly stress the suitability of $\mathrm{HCL}, \mathrm{CH}_{3} \mathrm{COOH}, \mathrm{NH}_{4} \mathrm{NO}_{3}, \mathrm{NaNO}_{3}, \mathrm{CaCl}_{2}$, DTPA and EDTA.

Despite the numerous advantages of single extraction procedures (simplicity and rapidity, as well as low costs of analysis), there is not one preferred method which would obligatorily ensure rapid verification of nutrient availability in compost. Such a problem is particularly significant in the case where we have a considerable pool of different extracts and a resulting extensive database describing quantities of microelements in composts. In such a situation, it is crucial to refer to specialist methods of statistical analysis, which may reliably identify the option of choice. 
Principal component analysis was used in this study to reduce a large number of variables to a much smaller number of independent principal components, and to enable the presentation of relationships among the extractors. By this method, the set of observations of correlated variables is converted into a set of linearly uncorrelated ones called principal components, whilst retaining as much as possible of the variation in the original variables. The number of principal components is less than or equal to the number of original variables. The new variables preserve a relatively large part of the information contained in the original data. Each one is a combination of observed variables and delivers some substantive content. Successive components explain a progressively smaller part of the total variance. Detailed descriptions of the method are given by Seber (1984), Morrison (1990), Krzyśko (2000) and Krzyśko et al. (2008).

In view of the above, studies were undertaken to select the most suitable extraction solution for the quantitative analysis of microelements in composts, using principal component analysis. The study included the verification of 10 different extractants which led to the detection of varied quantitative levels of essential micronutrients in composts of different compositions.

\section{Material and methods}

\subsection{Material}

The experiment was conducted on four different composts (C1-C4) produced by composting sewage sludge with the addition of such biowastes as straw, sawdust, pine bark, wood chips and hemp waste. Table 1 shows the percentage shares of the individual components in the mixtures. Quantities of added components were calculated on a dry matter basis.

A bulk sample was obtained by mixing 4-5 single samples collected from different sampling sites in individual composts. The collected material was dried at $40^{\circ} \mathrm{C}$ and then ground and sieved through a mesh size of $0.25 \mathrm{~mm}$. 
Samples thus prepared were analysed to determine contents of essential micronutrients $(\mathrm{Ni}, \mathrm{Cu}, \mathrm{Mn}, \mathrm{Zn}, \mathrm{Fe})$. Concentrations of nutrients in the extracts were determined using atomic absorption spectrophotometry (ASA) in a Varian Spectra AA 220

Table 1. Percentage share of individual components in composts

\begin{tabular}{lcccc}
\hline Component & C1 & C2 & C3 & C4 \\
\hline Sewage sludge & 75 & - & 39 & - \\
Wheat straw & 5 & - & 5 & - \\
Sawdust & 20 & - & 56 & - \\
\hline Sewage sludge & - & 40 & - & 40 \\
Sawdust & - & 10 & - & - \\
Pine bark & - & 50 & - & - \\
Wood cuttings & - & - & - & 10 \\
Hemp waste & - & - & - & 50 \\
\hline
\end{tabular}

FS apparatus. All assays identifying the amounts of nutrients in the tested compost samples were performed in three replications.

\subsection{Methods}

The one-step extractions were realised using 10 different extractants. The details of the experimental protocols are available elsewhere (Jakubus 2010, Queva-uviller et al. 1998, Zorpas et al. 2008). They are presented in brief in Table 2.

\subsection{Statistical formulation}

Principal component analysis is a procedure that converts the observations of correlated variables $\mathbf{X}_{i}, i=1,2, \ldots, k$, into new ones $\mathbf{Z}_{j}=\sum_{i=1}^{k} a_{j i} \mathbf{X}_{i}, j=1,2, \ldots, k$ , which are linearly uncorrelated and such that their total variance equals the sum of the variances of $\mathbf{X}_{i}$. The variables $\mathbf{Z}_{j}$ are called principal components, and $\operatorname{Var}\left(\mathbf{Z}_{1}\right) \geq \operatorname{Var}\left(\mathbf{Z}_{2}\right) \geq \ldots \geq \operatorname{Var}\left(\mathbf{Z}_{k}\right) \geq 0, \quad \operatorname{Cov}\left(\mathbf{Z}_{j}, \mathbf{Z}_{j}\right)=0, \quad j \neq j, \quad$ where $\operatorname{Var}\left(\mathbf{Z}_{j}\right)$ denotes the variance of the $j^{\text {th }}$ random variable in the population, 
and $\operatorname{Cov}\left(\mathbf{Z}_{j}, \mathbf{Z}_{j}\right)$ is the covariance between a pair of the principal components. The principal components determined for sample $\hat{\mathbf{Z}}_{j}$ have the form $\hat{\mathbf{Z}}_{j}=\sum_{i=1}^{k} \hat{a}_{j i} \mathbf{X}_{i}$, where $\hat{a}_{j i}$ are estimators of the coefficients $a_{j i}$, determined as the $i^{\text {th }}$ element of the $j^{\text {th }}$ eigenvector of the covariance matrix for the original variables $\mathbf{X}_{i}$. The eigenvalues represent the estimators of variance of the $j^{\text {th }}$ principal component $\hat{\mathbf{Z}}_{j}$. Moreover, the $j^{\text {th }}$ eigenvector

Table 2. One-step extraction protocols

\begin{tabular}{|c|c|c|}
\hline Extractor & $\begin{array}{l}\text { Compost: } \\
\text { solution ratio }\end{array}$ & Extraction procedures \\
\hline $\mathrm{I}-1 \mathrm{~mol} \mathrm{dm}^{-3} \mathrm{HCl}$ & $1: 20$ & $\begin{array}{l}\text { Shake } 1 \mathrm{~h} \text { at room temperature. Separate } \\
\text { the extract from the solid residue by } \\
\text { centrifugation for } 10 \text { minutes. }\end{array}$ \\
\hline $\mathrm{II}-0.5 \mathrm{~mol} \mathrm{dm}^{-3} \mathrm{HCl}$ & $1: 20$ & As above. \\
\hline $\begin{array}{l}\mathrm{III}-0.43 \mathrm{~mol} \mathrm{dm}^{-3} \\
\mathrm{CH}_{3} \mathrm{OOH}\end{array}$ & $1: 20$ & $\begin{array}{l}\text { Shake } 3 \mathrm{~h} \text { at room temperature. Separate } \\
\text { the extract from the solid residue by } \\
\text { centrifugation for } 10 \text { minutes. }\end{array}$ \\
\hline $\mathrm{IV}-1 \mathrm{~mol} \mathrm{dm}^{-3} \mathrm{NH}_{4} \mathrm{NO}_{3}$ & $1: 20$ & $\begin{array}{l}\text { Shake } 2 \mathrm{~h} \text { at room temperature. Separate } \\
\text { the extract from the solid residue by } \\
\text { centrifugation for } 10 \text { minutes. }\end{array}$ \\
\hline $\begin{array}{l}\mathrm{V}-0.05 \mathrm{~mol} \mathrm{dm}^{-3} \text { EDTA, } \\
\mathrm{pH}=7\end{array}$ & $1: 20$ & $\begin{array}{l}\text { Shake } 1.5 \mathrm{~h} \text { at room temperature. } \\
\text { Separate the extract from the solid } \\
\text { residue by centrifugation for } 10 \text { minutes. }\end{array}$ \\
\hline $\begin{array}{l}\mathrm{VI}-0.025 \mathrm{~mol} \mathrm{dm}^{-3} \\
\mathrm{Na}_{2} \text { EDTA, } \mathrm{pH}=4.62\end{array}$ & $1: 10$ & As above. \\
\hline $\begin{array}{l}\text { VII-FAC } 0.5 \mathrm{~mol} \mathrm{dm}^{-3} \\
\mathrm{CH}_{3} \mathrm{COOH}_{4}+\mathrm{CH}_{3} \mathrm{COOH} \\
\text { conc. }+0.02 \mathrm{~mol} \mathrm{dm}^{-3} \\
\text { EDTA, pH } 4.65\end{array}$ & $1: 20$ & $\begin{array}{l}\text { Shake } 1 \mathrm{~h} \text { at room temperature. Separate } \\
\text { the extract from the solid residue by } \\
\text { centrifugation for } 10 \text { minutes. }\end{array}$ \\
\hline VIII- $10 \% \mathrm{HNO}_{3}$ & $1: 20$ & $\begin{array}{l}\text { Shake } 3 \mathrm{~h} \text { at room temperature. Separate } \\
\text { the extract from the solid residue by } \\
\text { centrifugation for } 10 \text { minutes. }\end{array}$ \\
\hline $\begin{array}{l}\text { IX-DTPA }\left(0.005 \mathrm{~mol} \mathrm{dm}^{-3}\right. \\
\text { DTA }+0.1 \mathrm{~mol} \mathrm{dm}^{-3} \mathrm{TEA} \\
+0.01 \mathrm{~mol} \mathrm{dm}^{-3} \mathrm{CaCl}_{2}, \mathrm{pH} \\
7.3\end{array}$ & $1: 20$ & As above. \\
\hline $\mathrm{X}-0.01 \mathrm{~mol} \mathrm{dm}^{-3} \mathrm{CaCl}_{2}$ & $1: 20$ & As above. \\
\hline
\end{tabular}


of the covariance matrix corresponds to the $j^{\text {th }}$ largest eigenvalue of that matrix. The relevance of the principal components was examined using a scree graph; the point from which the graph is significantly flattened indicates the optimal number of components. STATISTICA 9.0 software was used for the statistical analysis.

\section{Results and discussion}

The data presented in Table 3 indicate that irrespective of the composition of the analysed compost, recorded amounts of all tested microelements were dependent above all on the extractant solutions used. In the present study single extractants were used, which were chemical solutions of different ionic strength, thus having different properties and extractabilities. These include hydrochloric, acetic and nitric acids, the salts calcium chloride and ammonium nitrate, as well as complexing compounds: DTPA, EDTA, $\mathrm{Na}_{2}$ EDTA, FAC. Acids are considered to be strong extraction solutions, with particularly high extractability observed for acetic and hydrochloric acids, separating components bound with the exchangeable fraction, the carbonate fraction, Fe-Mn oxides and organic matter. Acetic acid also leaches metals bound with the aforementioned fractions, although it is a much weaker extractant. Since acids, particularly $1 \mathrm{~mol}$ $\mathrm{dm}^{-3} \mathrm{HCl}$, do not provide the actual amounts of microelements which may be absorbed by plants, alternatives include the use of EDTA and DTPA. These compounds form a strong complex with the extracted metal, which enhances their efficiency (Jakubus 2009, Zou et al. 2009). EDTA is a strong, nonspecific extractant which can be used to determine metals both in the exchangeable fraction and bound with the non-exchangeable fractions (Feng et al. 2005). From the point of view of agricultural practice, a greater applicability is ascribed to the chelate DTPA, which facilitates determination of the current availability of micronutrients bound mainly to the exchangeable and carbonate fractions of the tested matrix. Moreover, it is recommended by the International Organization for Standardization (ISO) (Jakubus 2009). In the opinion of 
Gomez (1998), due to the relatively large amounts of microelements found in sewage sludge and composts, weak extractants may be used, such as $\mathrm{CaCl}_{2}$, which makes it possible to isolate only metals connected to the exchangeable fraction. As a result of the extraction of four different composts using solutions of different ionic strength, there was obtained a huge database, which was interpreted by principal component analysis. This statistical method, among others, made it possible to select the most as well as the least useful extractor for chemical analysis of composts in which the abundance of microelements is estimated from a practical point of view.

The usability of the principal components as linear combinations of the original variables which permit reduction of dimensionality with minimum loss of data variability is indicated in many examples considered by Czernyszewicz (2008), Kolasa-Więcek (2012), and Doria et al. (2012). This analysis has also been found useful in other studies, one of them being that described by Przybylski et al. (2002), in which interrelationships concerning pork meat quality were considered. For comparison, Kovacevic et al. (2010) investigated the relationship between 14 genotypes of black poplars with regard to the variability of 16 early rooting characteristics and cutting survival.

The analyses showed that, although single extractants are commonly used in chemical analyses of soils, they may also be successfully used in the qualitative evaluation of composts. Moreover, confirmation is provided for the literature reports presented above, indicating the varying suitability of particular solutions, manifested by different extracted quantities of nutrients. This is shown by the results, which were used in the principal component analysis mainly for individual composts in order to select the most suitable extraction solution, which is essential in analytical practice.

In our research, $k=10$. The choice of a subset of principal components was made according to the scree graph (Figures 1-4). Based on the statistical analysis, it can be seen that the first principal component is a general one, as it explains $99.98 \%$ of the total data variability for the first compost. Besides, the first principal component explains $99.97 \%$ of the total variability for the second 
compost, $99.94 \%$ for the third compost and $99.95 \%$ for the fourth compost. For comparison, Table 3 gives the percentage contribution of the variables for the above-mentioned ten solutions formed for composts $\mathrm{C} 1-\mathrm{C} 4$.

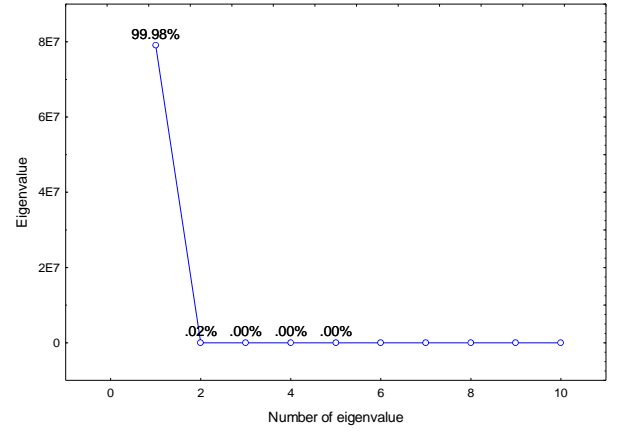

Figure 1. Scree graph for $\mathrm{C} 1$

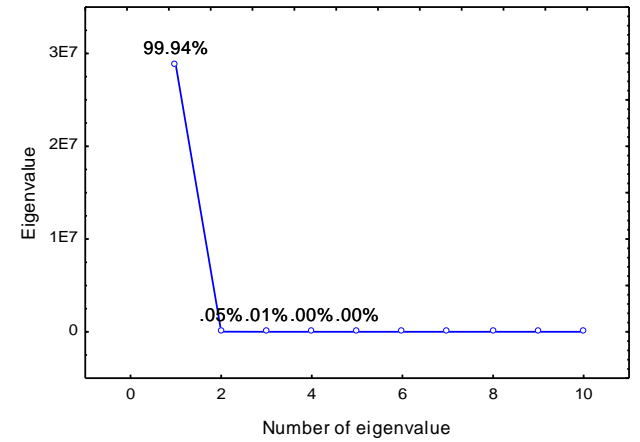

Figure 3. Scree graph for $\mathrm{C} 3$

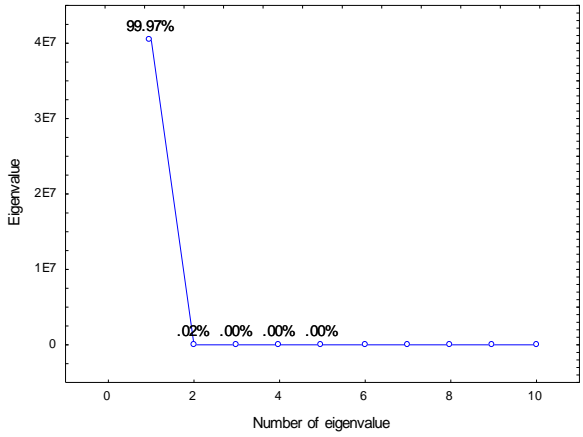

Figure 2. Scree graph for $\mathrm{C} 2$

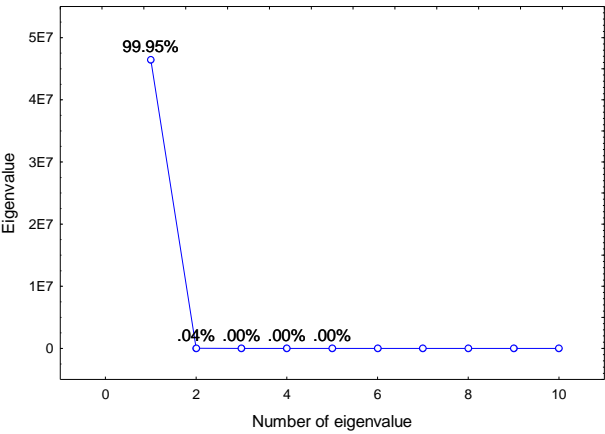

Figure 4. Scree graph for $\mathrm{C} 4$

The principal component analysis confirms the literature reports described above concerning the considerable extractability of acids, particularly hydrochloric and nitric acids. A markedly lower applicability in the quantitative assessment of microelements from composts produced using sewage sludge was found for the other tested solutions. This concerns particularly calcium chloride, ammonium nitrate and acetic acid. 
Table 3. Percentage contribution of variables for composts C1-C4

\begin{tabular}{|c|c|c|c|c|c|c|c|c|}
\hline \multirow{2}{*}{$\begin{array}{l}\text { Extra- } \\
\text { ctor }\end{array}$} & \multicolumn{2}{|c|}{$\mathrm{C} 1$} & \multicolumn{2}{|c|}{$\mathrm{C} 2$} & \multicolumn{2}{|c|}{$\mathrm{C} 3$} & \multicolumn{2}{|c|}{$\mathrm{C} 4$} \\
\hline & $S_{1}{ }^{*}$ & $\mathrm{~S}_{2}$ & $\mathrm{~S}_{1}$ & $\mathrm{~S}_{2}$ & $\mathrm{~S}_{1}$ & $\mathrm{~S}_{2}$ & $\mathrm{~S}_{1}$ & $\mathrm{~S}_{2}$ \\
\hline I & 30.6131 & 5.9990 & 23.2094 & 4.3288 & 39.4989 & 13.6765 & 37.7363 & 7.7158 \\
\hline II & 10.6906 & 0.0250 & 10.6721 & 0.8271 & 13.4414 & 6.7227 & 9.7752 & 2.7223 \\
\hline III & 0.0001 & 27.5105 & 0.0005 & 36.4521 & 0.0006 & 26.9764 & 0.0001 & 7.7816 \\
\hline IV & 0.0005 & 0.0353 & 0.0003 & 0.0141 & 0.0004 & 0.0347 & 0.0004 & 0.0094 \\
\hline V & 8.7082 & 13.2104 & 15.4285 & 16.6193 & 9.5389 & 26.7543 & 10.6425 & 8.7278 \\
\hline VI & 2.7286 & 34.7357 & 7.2256 & 2.6355 & 7.1930 & 18.8086 & 3.7068 & 33.4118 \\
\hline VII & 22.4685 & 2.0026 & 19.7438 & 6.3223 & 10.3885 & 2.9478 & 7.8369 & 24.6786 \\
\hline VIII & 24.6340 & 8.1621 & 23.6427 & 12.7556 & 19.7876 & 0.0547 & 30.2038 & 5.9092 \\
\hline IX & 0.1563 & 8.3142 & 0.0772 & 19.9769 & 0.1507 & 4.0224 & 0.0978 & 9.0429 \\
\hline$X$ & 0.0000 & 0.0054 & 0.0000 & 0.0683 & 0.0000 & 0.0017 & 0.0000 & 0.0006 \\
\hline
\end{tabular}

Here, the data can be plotted with respect to two dimensions, thus giving a straightforward visual representation of what the data look like, instead of appearing as a large mass of numbers to be digested. In view of the above considerations, a plot of the examined ten extractors for four composts with respect to the first two principal components is given in Figures 5-8. The vector directions indicate the influence of the examined extractors on the first two principal components; the vector lengths reflect the standard deviation. The correlations between the amounts of microelements obtained through extraction using ten chemical substances for each compost, based on the scalar products of the vectors, are given.

Now let us consider Table 3 and the positions on the biplot of the vectors corresponding to the variables for the first compost (Figure 5). It is noted that $1 \mathrm{~mol} \mathrm{dm}{ }^{-3} \mathrm{HCl}$ is strongly linked with the first principal component. Next, there is a strong link between the first principal component and $10 \% \mathrm{HNO}_{3}$, as well as FAC. We include $0.5 \mathrm{~mol} \mathrm{dm} \mathrm{dm}^{-3} \mathrm{HCl}$ and $0.05 \mathrm{~mol} \mathrm{dm}^{-3}$ EDTA in the group of extractors which are connected with first principal component to a lesser degree. The remaining factors, for which the coordinates in Figure 5 were close to zero, provide little differentiation of the quantity of extracted microelements 


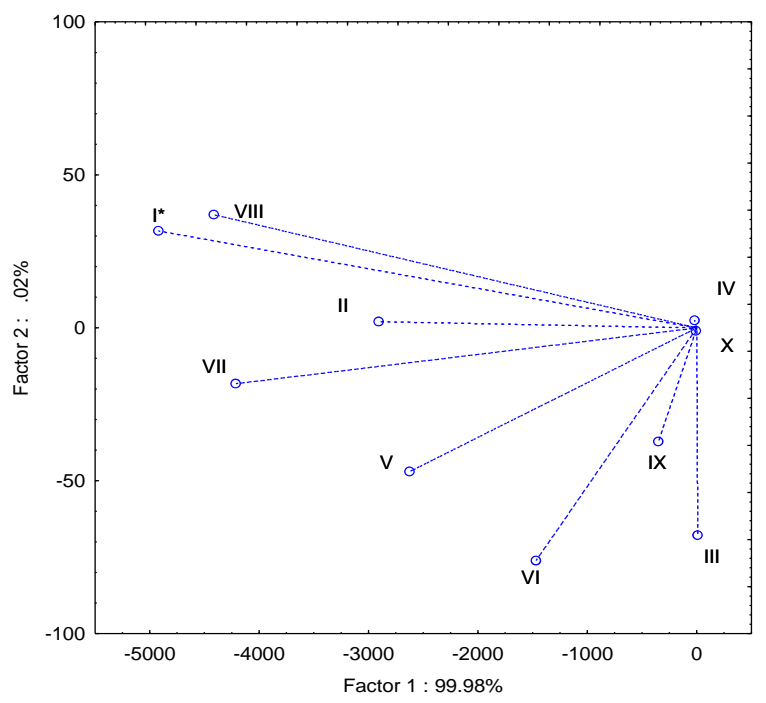

Figure 5. Relations of the 10 extractors based on the first two principal components formed for $\mathrm{C} 1,{ }^{*}$ notation according to Table 2

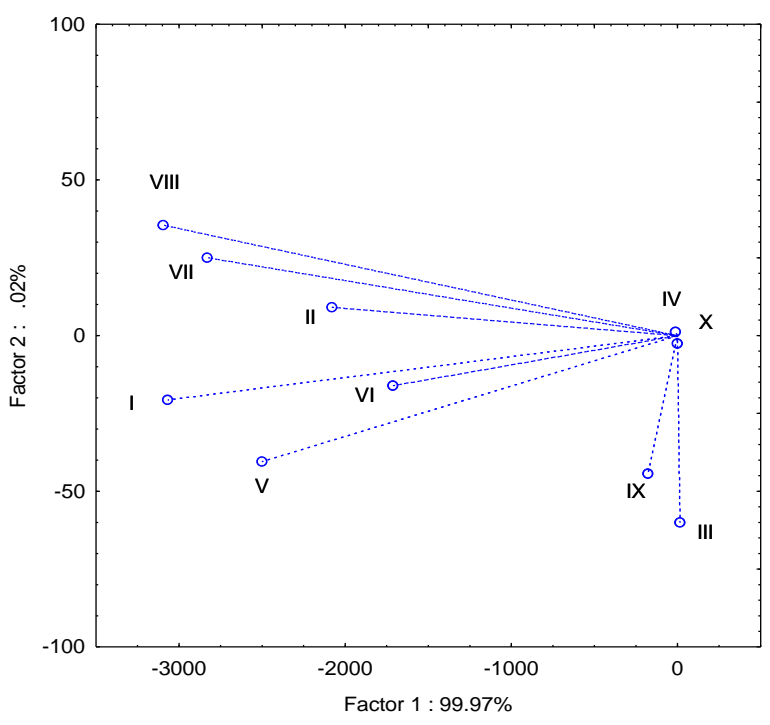

Figure 6. Relations of the 10 extractors based on the first two principal components formed for $\mathrm{C} 2$ 


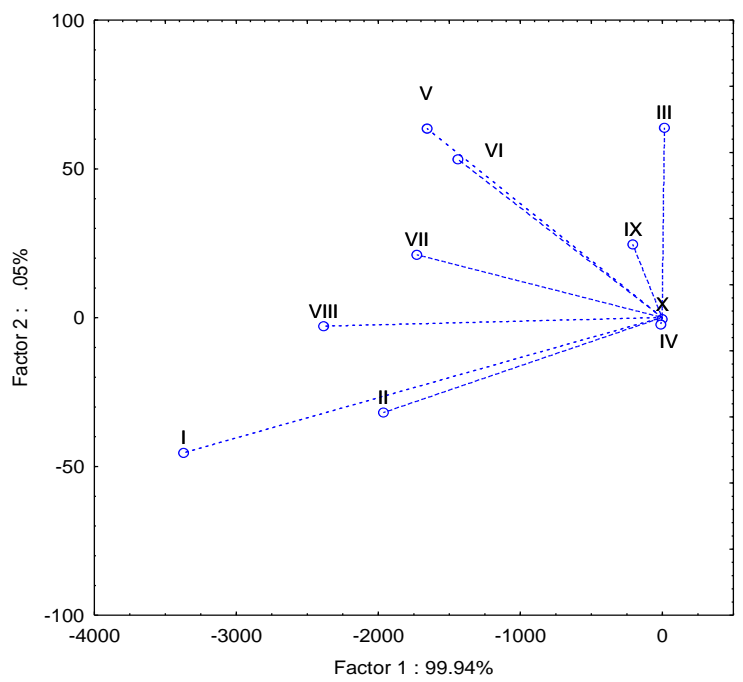

Figure 7. Relations of the 10 extractors based on the first two principal components formed for $\mathrm{C} 3$

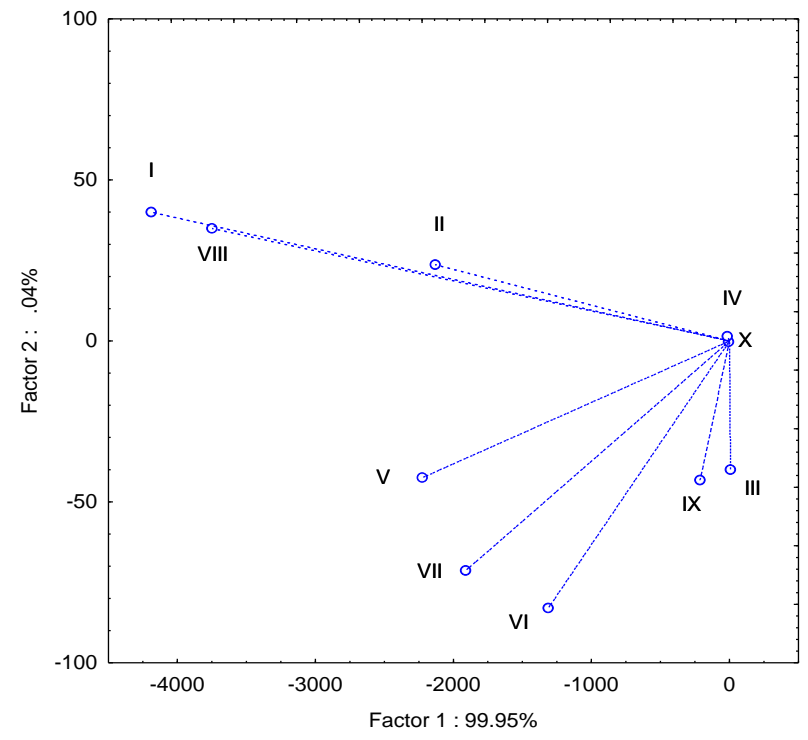

Figure 8. Relations of the 10 extractors based on the first two principal components formed for $\mathrm{C} 4$ 
among the group of examined chemical substances. This points to the weaker strength of extraction of such solutions as DTPA, $1 \mathrm{~mol} \cdot \mathrm{dm}^{-3} \mathrm{NH}_{4} \mathrm{NO}_{3}$, $0.43 \mathrm{~mol} \cdot \mathrm{dm}^{-3} \mathrm{CH}_{3} \mathrm{COOH}$ and $0.01 \mathrm{~mol} \cdot \mathrm{dm}^{-3} \mathrm{CaCl}_{2}$. Extracted amounts of microelements were correlated according to the applied chemical substance and the kind of compost. For the first compost, an example of such a relation was the quantity of microelements obtained using $1 \mathrm{~mol} \cdot \mathrm{dm}^{-3} \mathrm{HCl}$ and $10 \% \mathrm{HNO}_{3}$, likewise using $\mathrm{FAC}$ and $0.5 \mathrm{~mol} \cdot \mathrm{dm}^{-3} \mathrm{HCl}$. The amounts of microelements obtained as a result of extraction with $0.025 \mathrm{~mol} \mathrm{dm}^{-3} \mathrm{Na}_{2} \mathrm{NDTA}$ and $0.43 \mathrm{~mol} \cdot \mathrm{dm}^{-3} \mathrm{CH}_{3} \mathrm{COOH}$ were uncorrelated. It should be noted that the two last extractors are strongly linked with the second principal component, which explains $0.02 \%$ of the variability.

In the case of compost no. 2 the first principal component was significant, accounting for $99.97 \%$ of the total variation. It should be noted that $10 \% \mathrm{HNO}_{3}$ and $1 \mathrm{~mol} \cdot \mathrm{dm}^{-3} \mathrm{HCl}$ were strongly linked with this component, followed by FAC and $0.05 \mathrm{~mol} \cdot \mathrm{dm}^{-3}$ EDTA (Figure 6). The input of DTPA and acetic acid in the first component was unnoticeable. Both of these solutions were strongly relevant to the second principal component. The amounts of microelements obtained by the use of DTPA and acetic acid were uncorrelated with the amounts extracted by $10 \% \mathrm{HNO}_{3}, 1 \mathrm{~mol} \mathrm{dm}^{-3} \mathrm{HCl}, \mathrm{FAC}$ and $0.05 \mathrm{~mol} \mathrm{dm}^{-3}$ EDTA. The amounts of microelements extracted from $\mathrm{C} 2$ using the ammonium nitrate and calcium chloride solutions were close to zero, and consequently their contributions to the first two principal components were not significant. As mentioned above, in the case of the second compost, utilisation of $10 \% \mathrm{HNO}_{3}$ provides us with the most information about the amount of extracted microelements. Analysis of the data in Figure 6 indicates the relations between the extractors. There is a link between the quantities of microelements extracted by certain solutions. In view of this, it is worth noticing the strong link between the amounts of microelements obtained using $\mathrm{FAC}$ and $10 \% \mathrm{HNO}_{3}$, and further between $0.5 \mathrm{~mol} \cdot \mathrm{dm}^{-3} \mathrm{HCl}$ and two other extractors: $1 \mathrm{~mol} \cdot \mathrm{dm}^{-3} \mathrm{HCl}$ and $0.025 \mathrm{~mol} \cdot \mathrm{dm}^{-3} \mathrm{Na}_{2}$ EDTA . 
Although the chemical composition of compost no. 3 was characterised by the lowest share of sewage sludge and at the same time by the highest share of structural materials (Table 1), the first principal component, similarly as in the case of $\mathrm{C} 1$, was linked with $1 \mathrm{~mol} \cdot \mathrm{dm}^{-3} \mathrm{HCl}$, which was the best extractor in such conditions. However, in the situation of the third compost, the group of extractors linked with the first principal component was much larger, and included the following solutions: $10 \% \mathrm{HNO}_{3}, 0.5 \mathrm{~mol} \cdot \mathrm{dm}^{-3} \mathrm{HCl}, \mathrm{FAC}$ and $0.05 \mathrm{~mol} \mathrm{dm}^{-3}$ EDTA (Figure 7). Under the conditions of compost no. 3, the amounts of microelements extracted by $0.025 \mathrm{~mol} \mathrm{dm}^{-3} \mathrm{Na}_{2}$ EDTA and $0.05 \mathrm{~mol}$ $\mathrm{dm}^{-3}$ EDTA, and further by $1 \mathrm{~mol} \mathrm{dm} \mathrm{dm}^{-3}$ and $0.5 \mathrm{~mol} \mathrm{dm}^{-3}$, were correlated. The data presented in Figure 7 show that the amounts of microelements extracted by $0.05 \mathrm{~mol} \mathrm{dm}^{-3}$ EDTA and $0.025 \mathrm{~mol} \mathrm{dm}^{-3} \mathrm{Na}_{2}$ EDTA were uncorrelated, and did not have much influence on the variability of the first component. However, they make the biggest difference in the second principal component, which explains $0.06 \%$ of the variability. The coordinates related to the amounts of microelements extracted by calcium chloride, ammonium nitrate and DTPA based on the first two principal components were close to zero. These two solutions did not have any influence on the variability of the first two components.

Compost no. 4 , similarly as compost no. 2 , was characterised by a $40 \%$ share of sewage sludge (Table 1). In spite of this common property, it was found that a smaller spectrum of single extractants effectively extract microelements. Based on the data shown in Figure 8, the strongest extraction activity is exhibited by $1 \mathrm{~mol} \cdot \mathrm{dm}^{-3} \mathrm{HCl}$. A relatively large contribution to the total variation can be attributed to $10 \% \mathrm{HNO}_{3}$, even though, on the basis of the relations in the respective composts described up to now, the content of microelements extracted by $10 \% \mathrm{HNO}_{3}$ was the lowest. Regardless of the disparity between the amounts of obtained microelements, we should note the large correlation between the above-mentioned acid solutions. Considering the fact that the coordinates corresponding to the content of microelements extracted by acetic acid, ammonium nitrate, calcium chloride and DTPA for 
two first components are close to zero, these substances are not linked with the first and the second components. The smallest link with the first component was found for $0.025 \mathrm{~mol} \cdot \mathrm{dm}^{-3} \mathrm{Na}_{2} \mathrm{EDTA}$ and $\mathrm{FAC}$, although these were linked with the second principal component, which explains $0.04 \%$ of the total variability. In the fourth dataset described by the amounts of microelements extracted from compost no. 4 we can see that the amounts of microelements extracted using $0.025 \mathrm{~mol} \cdot \mathrm{dm}^{-3} \mathrm{Na}_{2}$ EDTA and FAC were correlated. At the same time, the amounts of microelements extracted using these solutions were uncorrelated with the amounts of microelements extracted with $1 \mathrm{~mol} \cdot \mathrm{dm}^{-3} \mathrm{HCl}, 0.5 \mathrm{~mol} \mathrm{dm} \mathrm{m}^{-3} \mathrm{HCl}$ and $10 \% \mathrm{HNO}_{3}$.

\section{Conclusions}

- The principal component analysis employed here made it possible to distinguish, among 10 chemical solutions, those with the highest extraction strength $\left(1 \mathrm{~mol} \mathrm{dm}{ }^{-3} \mathrm{HCl}\right.$ and $\left.10 \% \mathrm{HNO}_{3}\right)$ with respect to microelements present in composts, as well as those which did not provide significant information in this regard $\left(0.01 \mathrm{~mol} \mathrm{dm}^{-3} \mathrm{CaCl}_{2}, 1 \mathrm{~mol} \mathrm{dm}{ }^{-3} \mathrm{NH}_{4} \mathrm{NO}_{3}\right)$.

- The quantity fluctuation of microelements in composts no. 1, 3 and 4 was strongly determined by $1 \mathrm{~mol} \mathrm{dm}^{-3} \mathrm{HCl}$, and that in compost no. 2 by $10 \%$ $\mathrm{HNO}_{3}$.

- Based on the data obtained, the validity of using solutions with low extraction strength such as $0.01 \mathrm{~mol} \mathrm{dm}^{-3} \mathrm{CaCl}_{2}, 1 \mathrm{~mol} \mathrm{dm}^{-3} \mathrm{NH}_{4} \mathrm{NO}_{3}$ and $0.43 \mathrm{~mol} \mathrm{dm}^{-3} \mathrm{CH}_{3} \mathrm{COOH}$ in chemical analysis of composts should be questioned. Among the listed extractors, only $0.43 \mathrm{~mol} \mathrm{dm}^{-3} \mathrm{CH}_{3} \mathrm{COOH}$ had an influence on the variability of the second component for all investigated composts.

- Although the analysed composts differed in terms of the share of individual components, the first principal component was at a similar level, varying from $99.94 \%$ to $99.98 \%$, and explained the total variability fluctuation of the extraction strength of the analysed chemical compounds. 
- Principal component analysis of our data showed that regardless of the compost analysed, the amounts of microelements extracted with $1 \mathrm{~mol} \mathrm{dm}^{-3}$ $\mathrm{HCl}$ and $10 \% \mathrm{HNO}_{3}$ were comparable.

\section{REFERENCES}

Czernyszewicz E. (2008): Zastosowanie analizy składowych głównych do opisu konsumenckiej struktury jakości jabłek. ŻYWNOŚĆ. Nauka. Technologia. Jakość 2 (57): 119-127.

Doria I.P., Sousa Ferreira A., Dias O., Bacelar-Nicolau H., Le Calvè G. (2012): Comparison of multivariate analysis methodologies in a palliative care setting. Biometrical Letters 49(1): 67-79.

Feng M.-H., Shan X.-Q., Zhang S.-Z., Wen B. (2005): Comparison of rhizospherebased method with other one-step extraction methods for assessing the bioavailability of soil metals to wheat. Chemosphere 59: 939-949.

Fuentes A., Llorens M., Saez J., Soler A., Aguilar I., Ortuno J., Meseguer F. (2004): Simple and sequential extractions of heavy metals from different sewage sludges. Chemosphere 54: 1039-1047.

Gomez A. (1998): The evaluation of compost quality. Trends in Analytical Chemistry, 17 (5): 310-314.

Gupta A.K., Singh S. (2006): Chemical fractionation and heavy metal accumulation in the plant of Sesamum indicum (L.) var. T55 grown on soil amended with tannery sludge: Selection of single extractants. Chemosphere 64: 161-173.

Jakubus M. (2009): Zawartości Fe i Mn w glebie ekstrahowane roztworami o różnej sile jonowej podczas rozkładu kompostu. Zesz. Probl. Post. Nauk Roln. 541: 121-131.

Jakubus M. (2010): Changes of speciation and bioavailability of micronutrients during sewage sludge composting with different biowastes. Poznań University of Life Sciences, Scientific Researches 405, p. 156.

Jakubus M. (2012): Evaluation of compost by selected chemical and biological methods. Fresen. Environ. Bull. 21 (11a): 3464-3472.

Kolasa-Więcek A. (2012): Analiza składowych głównych w ocenie zależności sposobu użytkowania gruntów $\mathrm{z}$ emisją gazów cieplarnianych $\mathrm{z}$ rolnictwa. Inżynieria Rolnicza 2 (137): 105-112.

Kovacevic B., Cobanovic K., Orlovic S., Nikolić-Dorić E. (2010): Relationship among black poplar genotypes based on cutting rooting and survival - a multivariate approach. Biometrical Letters 47 (1): 15-323.

Krzyśko M. (2000): Wielowymiarowa analiza statystyczna. Wydawnictwo Naukowe UAM, Poznań.

Krzyśko M., Wołyński W., Górecki T., Skorzybut M. (2008): Systemy uczące się. Wydawnictwo Naukowo Techniczne, Warszawa. 
Meers E., Samson R., Tack F.M.G., Ruttens A., Vandegehuchte M., Vangronsveld J., Verloo M.G. (2007): Phytoavailability assessment of heavy metals in soils by single extractions and accumulation by Phaseolus vulgaris. Environ. Exp. Bot. 60: 385-396.

Morrison D. (1990): Wielowymiarowa analiza statystyczna. PWN, Warszawa.

Peijnenburg W.J.G.M., Jager T. (2003): Monitoring approaches to assess bioaccessibility and bioavailability of metals: Matrix issues. Ecotoxicology and Environmental Safety 56: 63-77.

Przybylski W., Mądry W., Koćwin-Podsiadła M. (2002): Zastosowanie analizy składowych głównych w badaniach nad jakością mięsa wieprzowego. Colloquium Biometryczne 32: 167-175.

Quevauviller Ph., Lachica M., Barahona E., Gomez A., Rauret G., Ure A., Muntau H. (1998): Certified reference material for the quality control of EDTA - and DTPA - extractable trace metals contents in calcareous soil (CMR 600). Fresen. J. Anality. Chem. 360: 505-511.

Rao C.R.M., Sahuquillo A., Lopez Sanchez F. (2008): A review of the different methods applied in environmental geochemistry for single and sequential extraction of trace elements in soils and related materials. Water, Air, and Soil Pollution 189: 291-333.

Seber W.G.A. (1984): Multivariate observations. J. Wiley, New York.

Zorpas A.A., Loizidou M. (2008): Sawdust and natural zeolite as a bulking agent for improving quality of a composting product from anaerobically stabilized sewage sludge. Bioresour. Technol. 99: 7545-7552.

Zou Z., Qiu R., Zhang W., Dong H., Zhao Z., Zhang T. (2009): The study of operating variables in soil washing with EDTA. Environmental Pollution 157: 229-236. 